\title{
Tertiary lymphoid structure and B-cell-related pathways: A potential target in tumor immunotherapy (Review)
}

\author{
MENG QIN $^{1,2}$, YING JIN ${ }^{1,2}$ and LING-YA PAN ${ }^{1,2}$ \\ ${ }^{1}$ Department of Obstetrics and Gynecology, Peking Union Medical College Hospital, Chinese Academy \\ of Medical Sciences and Peking Union Medical College; ${ }^{2}$ Department of Obstetrics and Gynecology, National \\ Clinical Research Center for Obstetric and Gynecologic Diseases, Beijing 100730, P.R. China
}

Received July 31, 2021; Accepted September 28, 2021

DOI: 10.3892/ol.2021.13097

\begin{abstract}
The tertiary lymphoid structure (TLS), also referred to as the ectopic lymphoid structure, has recently become a focus of attention. The TLS consists of T-cell and B-cell-rich regions, as well as plasma cells, follicular helper $\mathrm{T}$ cells, follicular dendritic cells (FDCs), germinal centers (GCs) and high endothelial venules. TLSs can be divided into different subtypes and mature stages according to the density of FDCs and GCs. The TLS serves as an effective site in which an antitumor inflammatory response is generated through infiltrating immune cells. B-cell-related pathways, known as the CXC chemokine ligand 13/CXC chemokine receptor type 5 axis and the CC chemokine ligand (CCL)19/CCL21/CC-chemokine receptor 7 axis, play a key role in the generation and formation of TLSs. The aim of the present review was to systematically summarize updated research progress on the formation, subtypes, evaluation and B-cell-related pathways of TLSs. Furthermore, researchers have previously reported that TLSs are present in several types of solid cancers and that they are associated with survival outcomes. Therefore, studies on TLS in breast, lung, colorectal and ovarian cancers and melanoma were summarized and compared. The TLS and B-cell-related pathways require further investigation as important immune signals and promising new immunotherapy targets in the era of T-cell therapy revolution.
\end{abstract}

\section{Contents}

1. Introduction

2. Definition of the TLS

Correspondence to: Dr Ling-Ya Pan, Department of Obstetrics and Gynecology, Peking Union Medical College Hospital, Chinese Academy of Medical Sciences and Peking Union Medical College, 9 Dongdan 3rd Street, Beijing 100730, P.R. China

E-mail: panly@pumch.cn

Key words: tertiary lymphoid structure, B cell, high endothelial venule, germinal center, tumor microenvironment, tumor immunotherapy
3. Subtypes and evaluation of the TLS

4. High endothelial venules

5. Germinal centers

6. B-cell-related pathways in the TLS

7. Progress on the TLS in different tumors

8. Conclusion

\section{Introduction}

The development of cancer in humans is a multistep programmed process that involves multiple gene mutations and genetic modifications and leads to uncontrolled cell division and apoptosis evasion. The accumulation of gene mutations results in the expression of tumor antigens, triggering the activation of innate and adaptive antitumor immune responses aimed at eliminating tumor cells (1). The tumor microenvironment (TME), a new concept for developing tumor markers, has been proposed and widely recognized for its important role (2). The dynamic interaction between tumor cells and immune cells controls tumorigenesis, local invasion and distant metastasis. Immune cells remain in situ or migrate as a response to different signals, further contributing to the formation of the overall TME (1).

The immune system of the host is the main target for antitumor immunotherapy. The accumulation of tumor immune cells contributing to tumor resistance is an important part of tumor genetics (3). There are several types of tumor-infiltrating immune cells, including T cells, B cells, dendritic cells (DCs), tumor-associated macrophages (TAMs) and natural killer (NK) cells. A core component of tumorigenesis is dysregulation of the immune system $(4,5)$. Tumor cells attempt to escape immune surveillance in different ways, resulting in ineffective immune surveillance. Immune cells provide a microenvironment for developing inflammation and tumor metastasis. Therefore, the basic strategy of tumor immunotherapy is always focused on how to avoid impaired immune surveillance and how to prevent damage to the immune system (6). The most typical example is the finding that the tumor-promoting function of regulatory/immunosuppressive immune cells depends on the inflammatory environment mediated by inflammatory cells, which can aggregate and alternately induce TAMs, regulatory $\mathrm{T}$ cells (Tregs) and myeloid-derived suppressor 
cells (MDSCs) (7-9). Therefore, achieving a comprehensive understanding of the TME is crucial.

T-cell-related pathways play an important role in immunotherapy and have been used for targeted tumor therapies, such as anti-programmed death 1, anti-programmed death ligand 1 (PD-L1), anti-cytotoxic T lymphocyte antigen-4 and chimeric antigen receptor T-cell therapy (10). Numerous studies have reported that the expression of PD-L1 is an independent risk factor for progression-free survival (PFS) and overall survival (OS) in patients with cancer and is negatively associated with $\mathrm{CD} 8^{+}$tumor-infiltrating lymphocytes (TILs) (10-13). It is generally believed that the typical T-cell-mediated antitumor immune response is initiated by DCs in the TME. At the same time, the tumor-inducing antigen is presented to $\mathrm{T}$ cells in the secondary lymphoid organs (SLOs), further activating antitumor $\mathrm{T}$ cells. Then, the $\mathrm{T}$ cells migrate back to the tumor tissue, thus eliminating the target antigen expressed on tumor cells. In addition, a number of TILs, including $\mathrm{CD}^{+}$and $\mathrm{CD} 4^{+}$ TILs, are closely associated with antitumor response and survival benefit (14-16).

As a key component of TILs, B cells also play an important role in the immune response, which has been an increasing focus of recent research. Tumor-infiltrating B lymphocytes (TIBs) may be observed in a variety of solid tumors $(5,17)$. TIBs serve a role in antitumor immunity by secreting tumor-specific antibodies and maintaining the function of the TLS. Current evidence shows that TIBs directly kill tumor cells and indirectly secrete immunoglobulins and proliferative T cells to inhibit tumor cell proliferation (18). B cells can produce an immunosuppressive phenotype that secretes IL-10, thus leading to tumor progression. Therefore, B cells and B-cell-related pathways may serve as tumor-related therapeutic targets, prompting future research breakthroughs in the field of tumor immunotherapy $(19,20)$. The association between TLSs and B cells will be explained below.

\section{Definition of the TLS}

Traditional SLOs, including the spleen, lymph nodes, tonsils, appendix and lymphoid tissues distributed throughout the body, are important parts of the immune system. The structures of different SLOs are nearly identical and include T-cell- and B-cell-rich regions, different DC subgroups and special stromal cells (21). During the development of an immune response, SLOs are affected by central lymphoid tissue, which is where colonization and proliferation of T cells and B cells occurs, such as the thymus and bone marrow (20). SLOs provide a three-dimensional environment for the interaction of different immune cells, thus generating an effective immune response (20). Several immune reactions occur in the spleen and this organ exerts indirect antitumor or anti-infection effects (22).

The tertiary lymphoid structure (TLS), also referred to as ectopic lymphoid tissue, has a structure similar to that of typical SLOs, with certain differences. The TLS consists of T-cell and B-cell-rich regions, as well as plasma cells (PCs), follicular helper $\mathrm{T}$ (Tfh) cells, follicular dendritic cells (FDCs) and germinal centers (GCs) (23), as shown in Fig. 1. There are also specialized post-capillary venules, termed high endothelial venules (HEVs), which are present in all SLOs and not only in the spleen (24). NK cells are absent from the TLSs, unlike SLOs $(20,25)$. Under chronic inflammatory conditions, such as autoimmune diseases, chronic infections, chronic graft rejection and tumors, the TLS can trigger an immune response independent of SLOs (26). The TLS serves as an effective site for the generation of an antitumor response of the human immune system and triggers an inflammatory response through immune cell infiltration. It was recently demonstrated that TLSs can be affected by the TME and factors such as proinflammatory cytokines and corticosteroid intake, which lead to a reduction in TLSs (27).

The development of TLSs first requires progressive maturation of immune cells, including the proliferation of B cells and differentiation to PCs, the maturation of DCs, and the induction of cytotoxic $\mathrm{T}$ cells and $\mathrm{CD} 4^{+} \mathrm{T}$ cells (28). The formation of TLSs may require three key factors to mediate B-cell and DC recruitment: i) Induction of lymphotoxin (LT) production; ii) secretion of lymphocyte chemokines, such as CC-chemokine ligand (CCL)19, CCL21 and CXC chemokine ligand (CXCL)13; and iii) growth of HEVs (21). CD4 ${ }^{+}$ lymphoid $\alpha 1 \beta 2$ (LT $\alpha 1 \beta 2)$-expressing lymphoid tissue inducer (LTi) cells and LT $\beta$ receptor (LT $\beta R$ )-expressing interstitial lymphoid tissue organizer (LTo) cells interact to produce adhesion molecules (intercellular adhesion molecule-1 and vascular cell adhesion molecule-1), chemokines, cytokines, HEVs and lymphatic vessels (29). In the TME, during TLS formation, activated chemokines induce the aggregation of $\mathrm{T}$ cells and B cells mediated by HEVs and DCs via lymphatic vessels, thus leading to homing and regionalization of lymphocytes (30). CXCL13, CCL19 and CCL21, in turn, promote the expression of LT $\alpha 1 \beta 2$ among LTi cells, leading to a continuous and stable cycle (29).

\section{Subtypes and evaluation of the TLS}

A number of researchers have discovered different TLS subtypes, but there has been no single standard to date. Posch et al (31) demonstrated that the formation of a TLS is more prominent and more common in patients with colorectal cancer (CRC) exhibiting high microsatellite instability and/or BRAF mutation after analyzing 109 specimens from patients with stage II or III CRC. The authors divided TLSs into three subtypes characterized by the density of FDCs and mature B cells as follows: i) Early TLS: Diffuse and mixed B cells and $\mathrm{T}$ cells or composed of dense lymphocyte clusters without FDC and GC reactions; ii) primary follicular-like TLS: Dense lymphocyte clusters with FDCs but no GC reactions; and iii) secondary follicular-like TLS: Dense lymphocyte clusters with FDCs and active GC reactions. They systematically developed a TLS immune system score for effectively identifying patients with CRC with a lower risk of recurrence. Similarly, Silina et al (32) evaluated 138 patients with non-small cell lung cancer (NSCLC) and divided TLSs into three to four subtypes. Kroeger et al (33) performed in-depth research on the TLS structure in patients with ovarian cancer. TLSs are divided into four subtypes characterized by their T-cell and B-cell lymphoid aggregates: i) Type I: Small and aggregated, including $\mathrm{CD} 8^{+} \mathrm{T}$ cells, $\mathrm{CD} 4^{+} \mathrm{T}$ cells, $\mathrm{CD} 20^{+}$ $\mathrm{B}$ cells and CD208 ${ }^{+}$DCs; ii) Type II: Large and diffuse, including $\mathrm{CD} 8^{+} \mathrm{T}$ cells, $\mathrm{CD} 4^{+} \mathrm{T}$ cells, $\mathrm{CD} 20^{+} \mathrm{B}$ cells and no mature DCs; iii) Type III: Developmental TLSs, including 


\section{Tumor nest}

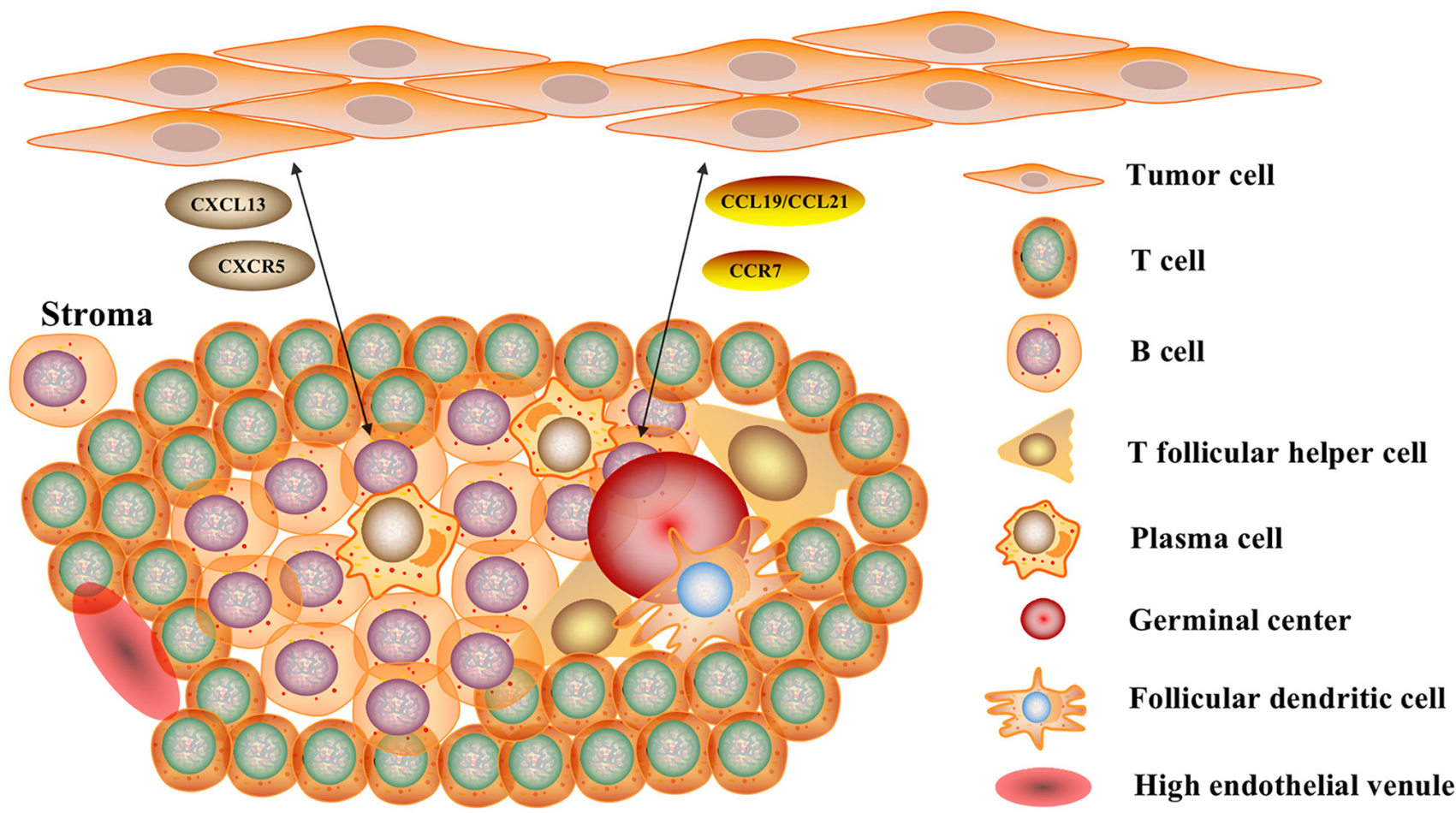

Figure 1. Structure of TLS and B-cell-related pathways. The TLS consists of T-cell- and B cell-rich regions, as well as plasma cells, follicular helper T cells, follicular dendritic cells and germinal centers. There are also specialized blood structures termed high endothelial venules. B-cell-related pathways serve a key role in the generation and formation of TLSs, the CXCL13/CXCR5 axis and the CCL19/CCL21/CCR7 axis. The TLS serves as an effective site for tumor reactions in the human immune system and triggers an inflammatory response through infiltrating immune cells. TLS, tertiary lymphoid structure; CXCL13, CXC chemokine ligand 13; CXCR5, CXC chemokine receptor type 5; CCL, CC chemokine ligand; CCR7, CC-chemokine receptor 7.

CD21 ${ }^{+}$FDCs, GC-related B-cell follicular masses and discrete T-cell regions; and iv) Type IV: CD20 ${ }^{+} \mathrm{B}$ cells, $\mathrm{CD} 21^{+} \mathrm{B}$ cells and CD $21^{+}$FDCs. These TLS subtype classifications can help to further understand the immune structure of TLSs in detail.

The location of the TLS has not been extensively researched in past studies. Hiraoka et al (34) evaluated the TLS by location and found that a superior outcome was observed in patients with an intratumoral TLS. Pancreatic cancer tissues with an intratumoral TLS exhibited significantly higher infiltration by $\mathrm{T}$ and $\mathrm{B}$ cells and lower infiltration by immunosuppressive cells, as well as higher expression of Th1- and Th17-associated genes. Thus, it is believed that the presence of an intratumoral TLS is associated with a TME with an active immune response and a complete vascular network.

Most recent studies reported that the presence of TLSs is usually associated with a survival benefit in solid tumors, but there are a few reports of TLSs as predictors of a poor prognosis. Bento et al (35) reported that the presence of HEVs at the infiltrative tumor margin is closely associated with advanced-stage disease in CRC. Figenschau et al (36) demonstrated that TLSs are associated with more aggressive tumors. Sofopoulos et al (37) studied 112 patients with breast cancer and found that patients with abundant peritumoral TLS had worse PFS and OS; thus, the density of the peritumoral TLS was a key prognostic factor. The importance of dynamic interactions between immune cells in the TME and the area surrounding the tumor tissues was recently emphasized. In addition, breast cancer patients with TLSs often have high-grade tumor pathological characteristics and a higher frequency of lymph node metastases (36). Therefore, there is currently no widely accepted TLS evaluation method, as these conflicting results must be further investigated to elucidate the underlying mechanism.

\section{High endothelial venules}

HEVs are specialized blood vessels found in all SLOs except the spleen. HEVs are formed during the embryonic and neonatal period and are mainly maintained by the lymphocyte microenvironment, which is the key to initiating and maintaining immune reactions (24). HEVs can extract naive and memory lymphocytes from the blood and transport them to antigen-presenting cells in the lymph nodes, regardless of the antigen receptor specificity. HEVs located outside the lymph nodes are found in lymphoid-dense tissues, which are called TLSs if combined with T-cell and B-cell-rich aggregates (38). Similar to traditional lymph nodes, HEVs regulate lymphocyte entry into lymphoid tissues. It has been reported that HEVs develop in non-lymphoid organs under conditions of chronic inflammation caused by autoimmunity, infection or allografts $(38,39)$. In addition, HEVs are widely found in highly vascular solid tumors, and the presence of HEVs is associated with reduced tumor growth and improved patient prognosis in breast cancer and melanoma (38). The density of HEVs is closely associated with tumor infiltration by $\mathrm{T}$ and B lymphocytes (40). In a study of 146 patients with breast cancer in situ, the density of HEVs was found to be associated with infiltration by naive, memory and granzyme-positive 
$\mathrm{CD}^{+} \mathrm{T}$ cells, as well as their related gene expression. The density of HEVs was associated with superior PFS and OS in patients with breast cancer with positive lymph nodes (41).

Some researchers believe that HEV neogenesis promotes antitumor immune reactions by accumulating immature lymphocytes in tumors, thus leading to devastating lymph node damage (42). Browning et al (43) indicated that triggering LT $\beta \mathrm{R}$ in endothelial cells can induce HEV differentiation in gene-targeted mice and that $\mathrm{CD} 11 \mathrm{c}^{+} \mathrm{DCs}$ play a key role in this process. Therefore, it is particularly important to determine whether signal transduction by LT $\beta R$ in endothelial cells drives the development of HEVs during tumorigenesis and to explore which molecules induce the formation of HEVs. Overall, blockade of the LT $\beta$ R leads to dedifferentiation of HEVs, but the components of this process remain unclear (43). In addition, HEV neogenesis may aggregate immunosuppressive cells, such as Tregs, which may suppress effective antitumor immune responses (44). These findings have revealed a new therapeutic approach by promoting the generation of HEVs and demonstrated the role of HEV neogenesis in tumor immunity.

Peripheral node addressin (PNAd) is an L-secretin/ CD62 L ligand that is a specific marker of HEVs. Although PNAd can be detected in some activated epithelial cells, it is not commonly expressed in other lymphatic vessels or lymphoid organs (45). It has been reported that PNAd ${ }^{+}$blood vessels exhibit the characteristics of HEV structures in breast cancer, ovarian cancer and melanoma (41). HEV development with PNAd expression was reported to occur prior to adenocarcinoma formation in a mouse model of gastric cancer with Helicobacter pylori infection (46). The effect of newly formed HEVs on tumor prognosis depends on whether there are sufficient DCs to present tumor-derived peptides to naive $\mathrm{T}$ cells in mature tumors and to induce sufficient activation of T cells. In a study of 225 primary melanomas, the density of HEVs was found to be closely associated with delayed tumor growth, as well as the presence of naive T cells, Th1-related genes and DCs expressing the maturation marker dendritic cell lysosome-associated membrane glycoprotein (DC-LAMP ${ }^{+}$). The association between HEV development and improved tumor immunity has been validated in mouse experiments (47). Vascular development with high PNAd expression levels is associated with reduced tumor growth, which leads to infiltration and local expansion of naive $\mathrm{T}$ cells and central memory $\mathrm{T}$ cells in tumors (48). Therefore, exploring the antitumor mechanism underlying the role of HEVs and determining whether they have the same function in multiple tumors is key for future research.

\section{Germinal centers}

The generation of GCs in TLSs is associated with increased autoimmunity, graft rejection and tumor immune responses. This is attributed to the generation of autoreactive B cells and HEVs (49). The GC reaction involves the migration of DCs expressing CC-chemokine receptor (CCR)7 (activated by NK cells) to the T-cell region of SLOs via the chemokines CCL19 and CCL21. Similarly, naive T cells expressing CCR7 are recruited by CCL19 and CCL21 to move through the HEVs to the T-cell region (50). DC-forming antigens respond to naive $\mathrm{T}$ cells and facilitate conversion from naive $\mathrm{T}$ cells to Tfh cells.
DCs present the antigens to naive $\mathrm{T}$ cells, thus accelerating conversion to Tfh cells. Along with the induction of CCR7 expression, CXCL13 produced by tumor mesenchymal cells migrates to the B-cell region, and Tfh cells gradually become mature, as indicated by the expression of the cytokine receptor CXC chemokine receptor type 5 (CXCR5) (49). Tfh cells, $\mathrm{B}$ cells and FDCs collectively promote the GC response during tumor activation, which leads to the differentiation of B cells into memory B cells and PCs (51). Posch et al (31) and Silina et al (32) showed that TLSs consist of CXCL13 ${ }^{+}$ peripheral blood vessels, CXCL12+ LT $\beta$ R-expressing cells, and PD-L1 ${ }^{+}$epithelial cells. The GC gradually grows along with the development of TLSs and eventually becomes an activated mature GC. In addition, the TLS density is associated with the formation of GCs and the expression of genes involved in the adaptive immune response. When comparing patients with lung cancer that had been treated with neoadjuvant chemotherapy or left untreated, GC formation was impaired, although the structure of the TLS was similar to that of the controls, and the prognostic ability of TLS density was eliminated (32). As mentioned above, some researchers have classified TLSs by GCs and FDCs and described the associations between the different subtypes of TLSs and patient survival (32). Therefore, GC formation in TLSs is crucial for tumor development and treatment.

\section{B-cell-related pathways in the TLS}

$B$-cell-related pathways in the TLS. The TLS is an ectopic lymphoid organ accompanied by a chronic inflammatory response in non-lymphoid tissues, and B-cell-related pathways play a key role in the generation and formation of TLSs $(20,52)$. As shown in Fig. 1, it has been reported that B-cell-related pathways, such as the pathways associated with CCR7 and CXCR5 in tumor cells, the CXCL13/CXCR5 axis and the CCL19/CCL21/CCR7 axis, promote tumor growth (20). In addition, B-cell-related pathways play an important role in the immune system through GCs in humans (5). Upregulation of TLSs may lead to significant antitumor responses. Therefore, $\mathrm{B}$ cells and B-cell-related pathways must be further explored as new immunotherapy targets (53).

The CXCL13/CXCR5 axis is activated under the interaction of B cells and Tfh cells to accelerate the GC response and participates in the migration of TIBs and Tfh cells in the TME (54). CXCR5 is mainly expressed in B cells, Tfh cells, mature DCs and tumor cells, and is necessary for cell migration. $\mathrm{CXCR}^{+}$cells are attracted by CXCL13-rich B cells, which are stimulated to mature by Tfh cells and FDCs (55). CXCL13, a B-lymphocyte chemotactic agent, is released from the B-cell interstitial region of SLOs. B cells mainly secrete LT, which promotes surrounding mesenchymal cells to induce CXCL13 (20,56). Furthermore, Tfh-like cells, FDCs and tumor cells can generate CXCL13, which induces B cells and Tfh cells to mature in the TME. Gu-Trantien et al (56) demonstrated that CXCL13 expression is associated with the presence of TLSs, high sensitivity to neoadjuvant chemotherapy and more favorable prognosis in breast cancer. Therefore, TGF $\beta$ can coordinate the immune response against human tumors, and $\mathrm{CXCL}_{13}{ }^{+} \mathrm{CD} 103^{+} \mathrm{CD}^{+}$TILs play an important role in mediating B-cell aggregation and TLS formation (54). 
On the other hand, high expression of CXCL13 and CXCR5 has also been associated with poor prognosis in certain tumor cells, such as CRC, gastric cancer and breast cancer cells (49). The CXCL13/CXCR5 axis in tumor cells is also involved in tumor cell proliferation and metastasis. It has been reported that CXCL13 increased cell migration and tumorigenicity via the NF- $\kappa B$ pathway in a mouse model of prostate cancer. In addition, Biswas et al (57) indicated that the combined expression of CXCL13 and CXCR5 was significantly associated with lymph node metastasis in patients with breast cancer. A high level of CXCL13 in the serum is considered an indicator of good prognosis for hepatocellular carcinoma, but it is associated with poor prognosis in patients with prostate or breast cancer. These conflicting findings regarding the CXCL13/ CXCR5 axis may be attributed to the different TMEs, which can promote the interaction of different cancer types, progression stages, receptor-expressing cells, immune cells and tumor cells (58). The absence of CXCL13 or CXCR5 in prostate cancer cells can also affect their migration ability and tumorigenicity $(57,58)$.

The CCL19/CCL21/CCR7 axis was found to be active in immune cells, such as T cells, B cells and DCs, and to help cells migrate to SLOs or other tumor sites and activate the host cell response (59). CCR7 is mainly expressed in naive T cells, B cells and tumor cells, and it is important for cell migration (60). CCL19, an Epstein-Barr virus-induced molecular 1 ligand chemokine, is expressed by DCs and tumor cells. CCL21, a secondary lymphoid tissue chemokine, is expressed by HEVs, lymphatic endothelial cells (LECs) and tumor cells. CCL19 and CCL21 are expressed in the T-cell region of SLOs in the tumor stroma. It has been reported that the expression of CCL19 and CCL21 is beneficial for survival in patients with CRC (61). The CCL19/CCL21/CCR7 axis mediates the accumulation of immune cells in lymphoid and non-lymphoid tissues. However, naive T cells expressing CCR7 mainly recognize CCL19 and CCL21, which are produced by the $\mathrm{T}$-cell region of SLOs, and migrate similar to T cells via the HEVs (59).

On the other hand, it has been reported that CCL19 or CCL21 produced by tumor cells is associated with tumor invasion and immune tolerance (62). The CCL19/CCL21/ CCR7 axis is activated in this manner, in which tumor cells are attracted towards $\mathrm{T}$ cells via chemokines. This leads to lymph node metastasis and poor survival outcomes. Tumor cells expressing CCR7 migrate towards LECs expressing CCL21 due to CCL19 and CCL21 secretion by autocrine tumor cells (63). In addition, intratumoral vaccination with a CCL21-expressing gene vector can result in the induction of systemic tumor antigen-specific immune responses (64). Shields et al (60) knocked out CCL21 in a melanoma model and found that CCL21-deficient tumors grew more slowly and triggered tumor-specific T-cell responses. Sperveslage et al (65) observed that CCR7 was upregulated in pancreatic ductal adenocarcinoma (PDAC) and was associated with tumor progression, lymph node metastasis and poor prognosis.

$B$-cell-related immunotherapy in the TLS. TLSs can coordinate the infiltration and activation of immune cells to produce an immunogenic TME to eliminate tumors. Immunotherapy that induces the formation of TLSs has been reported, and related immune vaccines are under development (27). Lutz et al (66) reported that formation and increased number of TLSs were observed in the majority of patients with PDAC treated with a granulocyte-macrophage colony-stimulating factor-secreting, allogeneic PDAC vaccine (GVAX) with cyclophosphamide (Cy). The purpose of this treatment was to inhibit Tregs and increase the numbers of Th17 cells. A corresponding study also proved that Tregs can prevent Th17 cells from promoting the formation of TLSs. In a phase II clinical trial, GVAX/Cy with CRS-207 (live, attenuated Listeria monocytogenes-expressing mesothelin) prolonged the survival of patients with PDAC (66). In addition, neoadjuvant chemotherapy was able to restore the formation of GCs in TLSs in patients with lung cancer, leading to the upregulation of TLS development and improving patient survival (32). Schrama et al (67) demonstrated that LT- $\alpha$ promoted the development of TLSs in a melanin mouse model.

To develop a clinically effective immunotherapy method for solid tumors, the key is to enhance the delivery of targeted lymphocytes to the tumor site and ensure the full expansion of activated lymphocytes in the immunosuppressive TME. Johansson-Percival et al (68) established a new method for inducing the formation of TLSs and blood vessels in tumors, which can enhance the effectiveness of immunotherapy for drug-resistant tumors. The authors designed a compound composed of mouse LIGHT protein and carboxy-terminal vascular targeting peptide (VTP) to specifically introduce LIGHT signals into tumor blood vessels to induce the formation of TLSs in the tumor. Following injection of LIGHT-VTP, immunohistochemistry and immunofluorescence detection showed that TLSs appeared in pancreatic tumors. Among proinflammatory cytokines and chemokines, IL-6, IL-1 $\beta$ and CCL21 are keys to inducing TLS $(1,4)$. Adaptive transfer experiments show that the formation and maintenance of TLSs require macrophages and T cells (1). In vivo studies demonstrated that LIGHT-VIP leads to an antitumor immune response. More immune cells infiltrate the tumor site and induce more effector T cells and memory T cells (68). Although LIGHT-VIP enhances the therapeutic efficacy of immune checkpoint inhibitors, the antitumor immune response is most effective when used in combination with tumor vaccines and checkpoint inhibitor therapy. The fusion protein formed by the combination of LIGHT and anti-EGFR antibody was also used in a previous study, which can specifically target $\mathrm{EGFR}^{+}$tumor cells (69). This treatment increases the expression of various cytokines and chemokines in the TME by activating LT $\beta$ R in interstitial cells, leading to increased T-cell infiltration and the formation of a proinflammatory T-cell TME.

\section{Progress on the TLS in different tumors}

Breast cancer. There has been substantial research progress on TLSs in breast cancer to date (70). In HER2-positive and triple-negative breast cancer (TNBC), the presence of a TLS is associated with superior survival outcomes, whereas the density and distribution of TLSs are key factors in prognosis and are taken into consideration in the pathological diagnosis of ductal carcinoma in situ (71). Liu et al (72) analyzed 248 patients with breast cancer and found that TLSs were associated with high-grade tumor pathology, apocrine phenotype, lymphovascular space invasion, high numbers of TILs, negativity for 
gonadal steroid hormone receptors, and positivity for HER2 and c-kit expression. In HER $2^{+}$breast cancer, TLSs have been found to be significantly associated with more favorable PFS and have no association with TILs, indicating that TLSs may be an independent and beneficial factor for PFS $(41,72)$.

The relationship between breast cancer and B cells is an attractive research topic. Garaud et al (73) analyzed the humoral immune response and signaling pathways of TIBs in breast cancer. In this study, the increase in TIB density is related to highly proliferative $\mathrm{CD}^{+}$and $\mathrm{CD} 8^{+}$TILs, as well as hormone receptor-negative disease, in which TIBs increased most significantly. TIBs respond to the stimulation of B-cell receptors in vitro, express activation markers and produce cytokines, despite the reduction in antigen-presenting HLA-DR and CD40 molecules. Finally, some authors believe that the sustained humoral immune response is generated by TIBs and helps to improve antitumor immunity at the tumor site (73). Jézéquel et al (74) performed DNA chip analysis on 238 patients with TNBC and used external data with the same DNA chip $(n=257)$ for verification. The external data were obtained from Gene Expression Omnibus (GEO) and ArrayExpress, and provided a large sample size. The study researched the infiltration by PCs and B cells, as well as TLS structure and neurogenesis, by histological evaluation. Three molecular clusters in TNBC were finally identified: One molecular apical secretion (C1) and two basal-like enrichments ( $\mathrm{C} 2$ and $\mathrm{C} 3)$. $\mathrm{C} 3$ exhibited an adaptive immune response associated with complete B-cell differentiation and immune checkpoint upregulation in TLSs, which could represent a specific targeted therapy (74).

The association between CXCL13 and Tregs has been previously reported in breast cancer (37). Gu-Trantien et al (56) found that tumor-infiltrating CXCL13 (CXCR5-) Tfh cells (TFHX13 cells) can promote local memory B-cell differentiation and are a key factor in transforming Tregs. TFHX13 cells can induce the formation of TLSs and accumulate GCs at the tumor site, thus promoting the B-cell antitumor response. Freier et al (75) found that the expression of CCL22 was positively associated with infiltration by FOXP $3^{+}$Tregs, FOXP3 being a Treg-specific transcription factor. Gobert et al (76) also reported that $\mathrm{FOXP}^{+}$Treg infiltration in TLSs in primary breast cancer suggested a higher risk of relapse and breast cancer-related death. The main characteristic of Tregs was the $\mathrm{CD} 4{ }^{+} \mathrm{CD} 25^{\text {high }} \mathrm{CD} 127^{\text {low }} \mathrm{FOXP} 3^{+}$phenotype, which was inhibited by in vitro stimulation through CCR4. Tregs can be selectively aggregated via CCR4 and then activated by mature DCs through tumor-associated antigens, which can prevent effector T-cell activation and ultimately lead to immune escape and tumor progression (76).

Lung cancer. There has been an increasing number of reports on TLS research in lung cancer (77). Dieu-Nosjean et al (78) first reported the presence of TLSs in NSCLC, and they named these structures tumor-induced bronchus-associated lymphoid tissue (Ti-BALT). Mature DCs (DC-LAMP ${ }^{+}$are a specific component of Ti-BALT, and their density is highly associated with tumor infiltration by $\mathrm{CD}^{+}$and $\mathrm{T}$-bet ${ }^{+} \mathrm{Th} 1$ cells, which is also associated with survival outcomes. Goc et al (79) also found that tumors infiltrated by TLS-associated mature DCs generate a specific immune contexture characterized by
Th1 cells and cytotoxic cytokines that reduces the mortality risk. Patients with large numbers of $\mathrm{DC}-\mathrm{LAMP}^{+}$mature DCs exhibit improved survival, although $\mathrm{T}$ cells (including naive and central memory $\mathrm{CD}^{+}$and $\mathrm{CD}^{+} \mathrm{T}$ cells) can be identified in the TLS. Therefore, the density of mature DCs is more important for response strength than the infiltration by $\mathrm{T}$ cells (79).

NSCLC is characterized by a close association between TLSs and T cells (80). Kim et al (81) retrospectively analyzed whether high TIL number was significantly associated with histological grade, abundant TLSs and the presence of GCs, which is an independent factor for improved PFS. Zhu et al (82) performed gene analysis on samples from 47 patients with NSCLC and found that $\mathrm{CD} 4^{+}$and $\mathrm{CD} 8^{+} \mathrm{T}$-cell sequences had higher clonality than $\mathrm{CD} 19^{+} \mathrm{B}$-cell sequences. The clonal expansion of $\mathrm{CD}^{+}{ }^{+} \mathrm{T}$-cell receptors in tumors is associated with a high density of B cells. In addition, Tregs in tumor-associated TLSs suppress antitumor immune responses in mouse models of lung cancer (82). de Chaisemartin et al (83) researched the formation and structure of TLSs in patients with NSCLC and found that TLSs mostly consist of $\mathrm{CD} 62 \mathrm{~L}^{+}$and $\mathrm{CD} 4^{+}$memory T-cell phenotypes, while naive $\mathrm{T}$ cells are highly enriched. The expression of specific genes, including most chemokines, adhesion molecules and integrins, is associated with the presence of $\mathrm{T}$ cells in TLSs. It has been confirmed that there are corresponding T-cell receptors in TLSs. TLSs are associated with endothelial vessels highly expressing PNAd in tumors and synergism with $\mathrm{CD} 62 \mathrm{~L}^{+}$lymphocytes.

$C R C$. TLSs have been observed in intratumoral spaces, peritumoral areas and at the invasive tumor front in CRC. There are several different types of immune cells in the TLS of CRC, including T cells, B cells, CD21 ${ }^{+}$FDCs, mature DCs and $\mathrm{CD} 31^{+}$cells in HEVs (84). It has been reported that the density of TLSs is related to immune cell infiltration, which can predict a more favorable prognosis for patients with stage II CRC (85-87). Weinstein et al (88) studied 33 CRC cases and found that IL-36 $\gamma$ expression was associated with memory $\mathrm{CD}^{+} \mathrm{T}$-cell infiltration, increased B-cell density and fibrous degeneration in TLSs. The expression of IL-1F5, a signaling antagonist of IL-36, is related to the expression of immune checkpoint inhibitors. In addition, $\mathrm{CD} 11 \mathrm{c}^{+} \mathrm{DCs}$ play a key role in inducing lymphangiogenesis in TLSs (89).

B cells exert an important antitumor effect on CRC (5). A T-cell rich TLS can be found in low-risk CRC, which indicates that the presence of TLSs in the local TME enhances the immune status for tumor rejection (90). Meshcheryakova et al (91) studied the biological mechanism of liver metastasis in CRC using microscopic imaging scans, lineage markers and single-cell technology. They found that densely infiltrating $\mathrm{CD} 20^{+} \mathrm{B}$ cells and a TLS positive for activation-induced cytidine deaminase $\left(\mathrm{AID}^{+}\right)$accumulated near the liver tumor margin. Schweiger et al (92) studied 57 patients with CRC metastatic to the pulmonary system and found an active immune microenvironment with infiltrating $\mathrm{CD}^{+}, \mathrm{CD}^{+}$and $\mathrm{CD} 45 \mathrm{RO}^{+}$and $\mathrm{FOXP} 3^{+}$TILs. In addition, the formation of B-cell follicles can be observed in sites of chronic inflammation, which is related to colorectal tumors (91). Since chronic inflammation is involved in the development of $\mathrm{CRC}$, it is difficult to determine whether TLSs contribute to 
tumor-related inflammatory responses or antitumor effects. TLSs may be the sites where immune cells migrate to in order to elicit an effective antitumor immune response (87).

Ovarian cancer. There have been a number of studies on TILs and TLSs in ovarian cancer (93). Kroeger et al (33) thoroughly researched the TLS structure of ovarian cancer. As previously mentioned, TLS-like lymphoid aggregates are divided into four subtypes characterized by $\mathrm{T}$ cells and $\mathrm{B}$ cells, ranging from small diffuse aggregates to large dense clusters. TLSs are often surrounded by dense PC infiltration, which accounts for $90 \%$ of the tumor stroma. PCs are associated with large numbers of $\mathrm{CD}^{+}, \mathrm{CD}^{+}$and $\mathrm{CD} 20^{+}$TILs and a large number of cytotoxin gene products, indicating that TLSs promote the synergistic antitumor response of $\mathrm{T}$ cells and PCs (33). Truxova et al (94) studied 81 patients with ovarian cancer and found that high-density tumor-infiltrating DC-LAMP ${ }^{+}$DCs characterized by Th1 polarization and cytotoxic activity are closely involved in the immune environment. They found that mature DCs and CD $20^{+}$B cells serve a key role in the cytotoxic immune response in the ovarian cancer TME. Gooden et al (93) retrospectively studied 270 ovarian cancer cases and 150 cervical cancer cases and found that the expression level of the HLA-E protein in $80 \%$ of tumor tissues was the same or even higher compared with that in normal epithelial tissue. When $\mathrm{CD}^{+}$TILs are combined with low HLA-E expression and inhibition of the CD94/NKG2A receptor in the TME, the survival of patients with ovarian cancer improves (93).

Melanoma. The presence of TLSs in primary melanoma is associated with superior survival outcomes. Ladányi et al (95) found that dense infiltration by peritumoral $\mathrm{CD}^{+} \mathrm{a}^{+}$and $\mathrm{DC}_{-} \mathrm{LAMP}^{+}$cells is combined with high density of CD25+ and $\mathrm{OX} 40^{+}$lymphocytes, which is associated with a good survival outcome. The combination of mature DCs and activated $\mathrm{T}$ cells mediates a functional immune response, thus providing prognostic information (26). Similarly, TLSs are also associated with metastatic melanoma. Cabrita et al (26) found that $\mathrm{CD}^{+} \mathrm{T}$ cells and $\mathrm{CD} 20^{+} \mathrm{B}$ cells effectively cooperate to improve the survival of patients with metastatic melanoma. CXCR5 and CXCL13 have similar mechanisms of action, which promotes the formation of TLSs in $\mathrm{CD} 8^{+} \mathrm{CD} 20^{+}$ tumors. Cipponi et al (96) focused on the complex structure of the TLS in 29 metastatic melanoma cases, including the $\mathrm{T}$-cell region rich in mature $\mathrm{DCs}$, unique $\mathrm{B}$-cell regions, HEVs and GCs. B-cell-mediated k-antibodies were activated with melanoma specificity, which is required for Ig somatic hypermutation and affinity maturation of enzymes (96). In addition, B-cell-rich tumors are accompanied by large numbers of $\mathrm{TCF}^{+}$naive $\mathrm{T}$ cells and memory $\mathrm{T}$ cells. In tumors without TLSs, T cells have a dysfunctional molecular phenotype (26). TLSs play a key role in the immune microenvironment of melanoma after attracting different T-cell subtypes. The expression of chemokines in melanoma cells is crucial for the induction of TLSs (30). Messina et al (97) performed 12-chemokine gene expression signature (GES) analysis of 14,492 solid tumor samples, including melanoma, and found that the presence of TLSs is directly associated with the 12-chemokine GES score. CCR7 ${ }^{+} \mathrm{LTi}$ cells aggregate in melanocytic tumors via CCL21 and promote the formation of TLSs. TLSs also aggregate immunosuppressive cells (such as $\mathrm{CD}^{+}$Tregs and MDSCs) to suppress the antitumor immune response. Tumor cells expressing CCL21 promote tumor cell proliferation by changing the TME, thus transforming the host's immune response from immunogenic to drug-resistant (98).

\section{Conclusion}

As a special ectopic lymphoid structure, the TLS plays an important role in the human immune system, and an association of the TLS with survival prognosis has been observed in different solid tumors. In-depth research on TLS formation and constitution may help further elucidate the molecular mechanisms at play in the TME. At present, the B-cell-related pathways of TLSs, known as the CXCL13/CXCR5 axis and the CCL19/CCL21/CCR7 axis, are extensively investigated. Inducing the formation of TLSs and inhibiting tumorigenesis via TLSs are expected to become research directions in the future. The TLS and corresponding B-cell pathways may come to represent novel antitumor targets in the era of T-cell therapy revolution.

\section{Acknowledgments}

Not applicable.

\section{Funding}

The present study was supported by The Fund of The National Key R\&D Program of China 2016YFC1303700 (Affiliated project 2016YFC1303701). Furthermore, this project was also supported by CAMS Innovation Fund for Medical Sciences (CIFMS-2017-I2M-1-002). Dr Meng Qin was supported by China Scholarship Council (grant no. 201906210463).

\section{Availability of data and materials}

Not applicable.

\section{Authors' contributions}

MQ, YJ and LYP equally contributed to the study conception and design and material preparation. The first draft of the manuscript was written by MQ, and all authors have critically revised the manuscript for important intellectual content. All the authors have read and approved the final manuscript.

\section{Ethics approval and consent to participate}

Not applicable.

\section{Patient consent for publication}

Not applicable.

\section{Competing interests}

The authors declare that they have no competing interests. 


\section{References}

1. Weinstein AM and Storkus WJ: Therapeutic lymphoid organogenesis in the tumor microenvironment. Adv Cancer Res 128 197-233, 2015.

2. Zhu G, Falahat R, Wang K, Mailloux A, Artzi N and Mulé JJ: Tumor-associated tertiary lymphoid structures: Gene-expression profiling and their bioengineering. Front Immunol 8: 767, 2017.

3. Becht E, Goc J, Germain C, Giraldo NA, Dieu-Nosjean MC, Sautès-Fridman C and Fridman WH: Shaping of an effective immune microenvironment to and by cancer cells. Cancer Immunol Immunother 63: 991-997, 2014

4. Sautès-Fridman C, Cherfils-Vicini J, Damotte D, Fisson S, Fridman WH, Cremer I and Dieu-Nosjean MC: Tumor microenvironment is multifaceted. Cancer Metastasis Rev 30: 13-25, 2011

5. Zhang Y, Gallastegui N and Rosenblatt JD: Regulatory B cells in anti-tumor immunity. Int Immunol 27: 521-530, 2015.

6. Sautès-Fridman C, Lawand M, Giraldo NA, Kaplon H, Germain C, Fridman WH and Dieu-Nosjean MC: Tertiary lymphoid structures in cancers: Prognostic value, regulation, and manipulation for therapeutic intervention. Front Immunol 7: 407, 2016.

7. Tan W, Zhang W, Strasner A, Grivennikov S, Cheng JQ, Hoffman RM and Karin M: Tumour-infiltrating regulatory T cells stimulate mammary cancer metastasis through RANKL-RANK signalling. Nature 470: 548-553, 2011.

8. Serafini P: Myeloid derived suppressor cells in physiological and pathological conditions: The good, the bad, and the ugly. Immunol Res 57: 172-184, 2013.

9. Khaled YS, Ammori BJ and Elkord E: Myeloid-derived suppressor cells in cancer: Recent progress and prospects. Immunol Cell Biol 91: 493-502, 2013.

10. Gadducci A and Guerrieri ME: Immune checkpoint inhibitors in gynecological cancers: Update of literature and perspectives of clinical research. Anticancer Res 37: 5955-5965, 2017.

11. Overman MJ, Lonardi S, Wong KYM, Lenz HJ, Gelsomino F, Aglietta M, Morse MA, Van Cutsem E, McDermott R, Hill A, et al: Durable clinical benefit with nivolumab plus ipilimumab in DNA mismatch repair-deficient/microsatellite instability-high metastatic colorectal cancer. J Clin Oncol 36: 773-779, 2018.

12. Thommen DS, Koelzer VH, Herzig P, Roller A, Trefny M, Dimeloe S, Kiialainen A, Hanhart J, Schill C, Hess C, et al: A transcriptionally and functionally distinct $\mathrm{PD}-1^{+} \mathrm{CD} 8^{+} \mathrm{T}$ cell pool with predictive potential in non-small-cell lung cancer treated with PD-1 blockade. Nat Med 24: 994-1004, 2018.

13. Buisseret L, Garaud S, de Wind A, Van den Eynden G, Boisson A Solinas C, Gu-Trantien C, Naveaux C, Lodewyckx JN, Duvillier $\mathrm{H}$, et al: Tumor-infiltrating lymphocyte composition, organization and PD-1/PD-L1 expression are linked in breast cancer. OncoImmunology 6: e1257452, 2016.

14. Lee YY, Choi CH, Sung CO, Do IG, Hub SJ, Kim HJ, Kim TJ, Lee JW, Bae DS and Kim BG: Clinical significance of changes in peripheral lymphocyte count after surgery in early cervical cancer. Gynecol Oncol 127: 107-113, 2012.

15. Piersma SJ, Jordanova ES, van Poelgeest MI, Kwappenberg KM, van der Hulst JM, Drijfhout JW, Melief CJ, Kenter GG, Fleuren GJ, Offringa R, et al: High number of intraepithelial CD8 ${ }^{+}$ tumor-infiltrating lymphocytes is associated with the absence of lymph node metastases in patients with large early-stage cervical cancer. Cancer Res 67: 354-361, 2007.

16. Wartenberg M,CibinS,ZlobecI, VassellaE,Eppenberger-CastoriS, Terracciano L, Eichmann MD, Worni M, Gloor B, Perren A, et al: Integrated genomic and immunophenotypic classification of pancreatic cancer reveals three distinct subtypes with prognostic predictive significance. Clin Cancer Res 24: 4444-4454, 2018.

17. Nielsen JS and Nelson BH: Tumor-infiltrating B cells and T cells Working together to promote patient survival. Oncoimmunology 1: 1623-1625, 2012.

18. Wang SS, Liu W, Ly D, Xu H, Qu L and Zhang L: Tumor-infiltrating B cells: Their role and application in anti-tumor immunity in lung cancer. Cell Mol Immunol 16: 6-18, 2019.

19. Lin $\mathrm{L}, \mathrm{Hu} \mathrm{X}$, Zhang $\mathrm{H}$ and $\mathrm{Hu} \mathrm{H}$ : Tertiary lymphoid organs in cancer immunology: Mechanisms and the new strategy for immunotherapy. Front Immunol 10: 1398, 2019.

20. Tokunaga R, Naseem M, Lo JH, Battaglin F, Soni S, Puccini A, Berger MD, Zhang W, Baba $\mathrm{H}$ and Lenz $\mathrm{HJ}$ : $\mathrm{B}$ cell and $\mathrm{B}$ cell-related pathways for novel cancer treatments. Cancer Treat Rev 73: 10-19, 2019.
21. Willard-Mack CL: Normal structure, function, and histology of lymph nodes. Toxicol Pathol 34: 409-424, 2006.

22. DiCaroG, Castino GF,Bergomas F, CorteseN,Chiriva-Internati M, Grizzi F, Mantovani A and Marchesi F: Tertiary lymphoid tissue in the tumor microenvironment: From its occurrence to immunotherapeutic implications. Int Rev Immunol 34: 123-133, 2015.

23. Dieu-Nosjean MC, Goc J, Giraldo NA, Sautès-Fridman C and Fridman WH: Tertiary lymphoid structures in cancer and beyond. Trends Immunol 35: 571-580, 2014.

24. Ager A and May MJ: Understanding high endothelial venules: Lessons for cancer immunology. OncoImmunology 4: e1008791, 2015.

25. Platonova S, Cherfils-Vicini J, Damotte D, Crozet L, Vieillard V, Validire P, André P, Dieu-Nosjean MC, Alifano M, Régnard JF, et al: Profound coordinated alterations of intratumoral NK cell phenotype and function in lung carcinoma. Cancer Res 71: 5412-5422, 2011.

26. Cabrita R,Lauss M,Sanna A,Donia M, SkaarupLarsen M,MitraS, Johansson I, Phung B, Harbst K, Vallon-Christersson J, et al: Tertiary lymphoid structures improve immunotherapy and survival in melanoma. Nature 577: 561-565, 2020.

27. Tang H, Qiu X, Timmerman C and Fu YX: Targeting tertiary lymphoid structures for tumor immunotherapy. Methods Mol Biol 1845: 275-286, 2018

28. Gu-Trantien C and Willard-Gallo K: Tumor-infiltrating follicular helper T cells: The new kids on the block. Oncoimmunology 2: e26066, 2013.

29. Jing F and Choi EY: Potential of cells and cytokines/chemokines to regulate tertiary lymphoid structures in human diseases. Immune Netw 16: 271-280, 2016.

30. Nerviani A and Pitzalis C: Role of chemokines in ectopic lymphoid structures formation in autoimmunity and cancer. J Leukoc Biol 104: 333-341, 2018.

31. Posch F, Silina K, Leibl S, Mündlein A, Moch H, Siebenhüner A, Samaras P, Riedl J, Stotz M, Szkandera J, et al: Maturation of tertiary lymphoid structures and recurrence of stage II and III colorectal cancer. OncoImmunology 7: e1378844, 2017.

32. Silina K, Soltermann A, Attar FM, Casanova R, Uckeley ZM, Thut H, Wandres M, Isajevs S, Cheng P, Curioni-Fontecedro A, etal: Germinal centers determine the prognostic relevance of tertiary lymphoid structures and are impaired by corticosteroids in lung squamous cell carcinoma. Cancer Res 78: 1308-1320, 2018.

33. Kroeger DR, Milne K and Nelson BH: Tumor-infiltrating plasma cells are associated with tertiary lymphoid structures, cytolytic T-cell responses, and superior prognosis in ovarian cancer. Clin Cancer Res 22: 3005-3015, 2016.

34. Hiraoka N, Ino Y, Yamazaki-Itoh R, Kanai Y, Kosuge T and Shimada K: Intratumoral tertiary lymphoid organ is a favourable prognosticator in patients with pancreatic cancer. Br J Cancer 112: 1782-1790, 2015.

35. Bento DC, Jones E, Junaid S, Tull J, Williams GT, Godkin A, Ager A and Gallimore A: High endothelial venules are rare in colorectal cancers but accumulate in extra-tumoral areas with disease progression. OncoImmunology 4: e974374, 2015.

36. Figenschau SL, Fismen S, Fenton KA, Fenton $\mathrm{C}$ and Mortensen ES: Tertiary lymphoid structures are associated with higher tumor grade in primary operable breast cancer patients. BMC Cancer 15: 101, 2015.

37. Sofopoulos M, Fortis SP, Vaxevanis CK, Sotiriadou NN, Arnogiannaki N, Ardavanis A, Vlachodimitropoulos D, Perez SA and Baxevanis $\mathrm{CN}$ : The prognostic significance of peritumoral tertiary lymphoid structures in breast cancer. Cancer Immunol Immunother 68: 1733-1745, 2019.

38. Jones E, Gallimore A and Ager A: Defining high endothelial venules and tertiary lymphoid structures in cancer. Methods Mol Biol 1845: 99-118, 2018.

39. Drayton DL, Liao S, Mounzer RH and Ruddle NH: Lymphoid organ development: From ontogeny to neogenesis. Nat Immunol 7: 344-353, 2006.

40. Song IH, Heo SH, Bang WS, Park HS, Park IA, Kim YA, Park SY, Roh J, Gong G and Lee HJ: Predictive value of tertiary lymphoid structures assessed by high endothelial venule counts in the neoadjuvant setting of triple-negative breast cancer. Cancer Res Treat 49: 399-407, 2017.

41. Martinet L, Garrido I, Filleron T, Le Guellec S, Bellard E, Fournie JJ, Rochaix P and Girard JP: Human solid tumors contain high endothelial venules: Association with T- and B-lymphocyte infiltration and favorable prognosis in breast cancer. Cancer Res 71: 5678-5687, 2011 
42. Onder L, Danuser R, Scandella E, Firner S, Chai Q, Hehlgans T, Stein JV and Ludewig B: Endothelial cell-specific lymphotoxin- $\beta$ receptor signaling is critical for lymph node and high endothelial venule formation. J Exp Med 210: 465-473, 2013

43. Browning JL, Allaire N, Ngam-Ek A, Notidis E, Hunt J, Perrin S and Fava RA: Lymphotoxin- $\beta$ receptor signaling is required for the homeostatic control of HEV differentiation and function. Immunity 23: 539-550, 2005.

44. Martinet L, Filleron T, Le Guellec S, Rochaix P, Garrido I and Girard J-P: High endothelial venule blood vessels for tumor-infiltrating lymphocytes are associated with lymphotoxin $\beta$-producing dendritic cells in human breast cancer. J Immunol 191: 2001-2008, 2013.

45. Uchimura K and Rosen SD: Sulfated L-selectin ligands as a therapeutic target in chronic inflammation. Trends Immunol 27: $559-565,2006$

46. Kobayashi M, Lee H, Schaffer L, Gilmartin TJ, Head SR, Takaishi S, Wang TC, Nakayama J and Fukuda M: A distinctive set of genes is upregulated during the inflammation-carcinoma sequence in mouse stomach infected by Helicobacter felis. J Histochem Cytochem 55: 263-274, 2007.

47. Martinet L, Le Guellec S, Filleron T, Lamant L, Meyer N, Rochaix P, Garrido I and Girard JP: High endothelial venules (HEVs) in human melanoma lesions: Major gateways for tumor-infiltrating lymphocytes. OncoImmunology 1: 829-839, 2012.

48. Hindley JP, Jones E, Smart K, Bridgeman H, Lauder SN, Ondondo B, Cutting S, Ladell K, Wynn KK, Withers D, et al: T-cell trafficking facilitated by high endothelial venules is required for tumor control after regulatory T-cell depletion. Cancer Res 72: 5473-5482, 2012.

49. Germain C, Gnjatic S and Dieu-Nosjean MC: Tertiary lymphoid structure-associated B cells are key players in anti-tumor immunity. Front Immunol 6: 67, 2015

50. Sautès-Fridman C, Petitprez F, Calderaro J and Fridman WH: Tertiary lymphoid structures in the era of cancer immunotherapy. Nat Rev Cancer 19: 307-325, 2019.

51. Clement M, Guedj K, Andreata F, Morvan M, Bey L, Khallou-Laschet J, Gaston AT, Delbosc S, Alsac JM, Bruneval $\mathrm{P}$, et al: Control of the $\mathrm{T}$ follicular helper-germinal center $\mathrm{B}$-cell axis by $\mathrm{CD}^{+}$regulatory $\mathrm{T}$ cells limits atherosclerosis and tertiary lymphoid organ development. Circulation 131: 560-570, 2015.

52. Petitprez F, de Reyniès A, Keung EZ, Chen TW, Sun CM, Calderaro J, Jeng YM, Hsiao LP, Lacroix L, Bougoüin A, et al: B cells are associated with survival and immunotherapy response in sarcoma. Nature 577: 556-560, 2020.

53. Silina K, Rulle U, Kalnina Z and Linē A: Manipulation of tumour-infiltrating B cell's and tertiary lymphoid structures: A novel anti-cancer treatment avenue? Cancer Immunol Immunother 63: 643-662, 2014.

54. Workel HH, Lubbers JM, Arnold R, Prins TM, van der Vlies P, de Lange K, Bosse T, van Gool IC, Eggink FA, Wouters MCA, et al: A transcriptionally distinct CXCL $13^{+} \mathrm{CD}_{103}{ }^{+} \mathrm{CD}^{+} \mathrm{T}$-cell population is associated with B-cell recruitment and neoantigen load in human cancer. Cancer Immunol Res 7: 784-796, 2019.

55. Morita R, Schmitt N, Bentebibel SE, Ranganathan R, Bourdery L, Zurawski G, Foucat E, Dullaers M, Oh S, Sabzghabaei N, et al: Human blood CXCR5(+)CD4(+) T cells are counterparts of T follicular cells and contain specific subsets that differentially support antibody secretion. Immunity 34: 108-121, 2011.

56. Gu-Trantien C, Migliori E, Buisseret L, de Wind A, Brohée S, Garaud S, Noël G, Dang Chi VL, Lodewyckx JN, Naveaux C, et al: CXCL13-producing TFH cells link immune suppression and adaptive memory in human breast cancer. JCI Insight 2: 2, 2017

57. Biswas S, Sengupta S, Roy Chowdhury S, Jana S, Mandal G, Mandal PK, Saha N, Malhotra V, Gupta A, Kuprash DV, et al: CXCL13-CXCR5 co-expression regulates epithelial to mesenchymal transition of breast cancer cells during lymph node metastasis. Breast Cancer Res Treat 143: 265-276, 2014.

58. Garg R, Blando JM, Perez CJ, Abba MC, Benavides F and Kazanietz MG: Protein kinase C epsilon cooperates with PTEN loss for prostate tumorigenesis through the CXCL13-CXCR5 pathway. Cell Rep 19: 375-388, 2017.

59. Pang MF, Georgoudaki AM, Lambut L, Johansson J, Tabor V, Hagikura K, Jin Y, Jansson M, Alexander JS, Nelson CM, et al: TGF- $\beta 1$-induced EMT promotes targeted migration of breast cancer cells through the lymphatic system by the activation of CCR7/CCL21-mediated chemotaxis. Oncogene 35: 748-760, 2016.
60. Shields JD, Fleury ME, Yong C, Tomei AA, Randolph GJ and Swartz MA: Autologous chemotaxis as a mechanism of tumor cell homing to lymphatics via interstitial flow and autocrine CCR7 signaling. Cancer Cell 11: 526-538, 2007.

61. Zou Y, Chen Y, Wu X, Yuan R, Cai Z, He X, Fan X, Wang L, Wu X and Lan P: CCL21 as an independent favorable prognostic factor for stage III/IV colorectal cancer. Oncol Rep 30: 659-666, 2013.

62. Hill DG, Yu L, Gao H, Balic JJ, West A, Oshima H, McLeod L, Oshima M, Gallimore A, D'Costa K, et al: Hyperactive gp130/ STAT3-driven gastric tumourigenesis promotes submucosal tertiary lymphoid structure development. Int J Cancer 143: $167-178,2018$

63. Pimenta EM and Barnes BJ: Role of tertiary lymphoid structures (TLS) in anti-tumor immunity: Potential tumor-induced cytokines/chemokines that regulate TLS formation in epithelial-derived cancers. Cancers (Basel) 6: 969-997, 2014.

64. Lee JM, Lee M-H, Garon E, Goldman JW, Salehi-Rad R, Baratelli FE, Schaue D, Wang G, Rosen F, Yanagawa J, et al: Phase I trial of intratumoral injection of CCL21 gene-modified dendritic cells in lung cancer elicits tumor-specific immune responses and $\mathrm{CD}^{+}{ }^{+} \mathrm{T}$-cell infiltration. Clin Cancer Res 23: 4556-4568, 2017

65. Sperveslage J, Frank S, Heneweer C, Egberts J, Schniewind B, Buchholz M, Bergmann F, Giese N, Munding J, Hahn SA, et al: Lack of CCR7 expression is rate limiting for lymphatic spread of pancreatic ductal adenocarcinoma. Int J Cancer 131: E371-E381, 2012.

66. Lutz ER, Wu AA, Bigelow E, Sharma R, Mo G, Soares K, Solt S, Dorman A, Wamwea A, Yager A, et al: Immunotherapy converts nonimmunogenic pancreatic tumors into immunogenic foci of immune regulation. Cancer Immunol Res 2: 616-631, 2014

67. Schrama D, Voigt H, Eggert AO, Xiang R, Zhou H, Schumacher TN, Andersen MH, thor Straten P, Reisfeld RA and Becker JC: Immunological tumor destruction in a murine melanoma model by targeted LTalpha independent of secondary lymphoid tissue. Cancer Immunol Immunother 57: 85-95, 2008.

68. Johansson-Percival A, He B, Li ZJ, Kjellén A, Russell K, Li J, Larma I and Ganss R: De novo induction of intratumoral lymphoid structures and vessel normalization enhances immunotherapy in resistant tumors. Nat Immunol 18: 1207-1217, 2017.

69. Tang H, Wang Y, Chlewicki LK, Zhang Y, Guo J, Liang W, Wang J, Wang $\mathrm{X}$ and Fu Y-X: Facilitating T cell infiltration in tumor microenvironment overcomes resistance to PD-L1 blockade. Cancer Cell 29: 285-296, 2016.

70. Gantsev SK, Umezawa K, Islamgulov DV, Khusnutdinova EK, Ishmuratova RS, Frolova VY and Kzyrgalin SR: The role of inflammatory chemokines in lymphoid neoorganogenesis in breast cancer. Biomed Pharmacother 67: 363-366, 2013.

71. Kim A, Heo SH, Kim YA, Gong G and Jin Lee H: An examination of the local cellular immune response to examples of both ductal carcinoma in situ (DCIS) of the breast and DCIS with microinvasion, with emphasis on tertiary lymphoid structures and tumor infiltrating lymphoctytes. Am J Clin Pathol 146: 137-144, 2016.

72. Liu X, Tsang JYS, Hlaing T, Hu J, Ni YB, Chan SK, Cheung SY and Tse GM: Distinct tertiary lymphoid structure associations and their prognostic relevance in HER2 positive and negative breast cancers. Oncologist 22: 1316-1324, 2017.

73. Garaud S, Buisseret L, Solinas C, Gu-Trantien C, de Wind A, Van den Eynden G, Naveaux C, Lodewyckx JN, Boisson A, Duvillier $\mathrm{H}$, et al: Tumor infiltrating B-cells signal functional humoral immune responses in breast cancer. JCI Insight 5: 5, 2019.

74. Jézéquel P, Kerdraon O, Hondermarck H, Guérin-Charbonnel C, Lasla H, Gouraud W, Canon JL, Gombos A, Dalenc F, Delaloge S, et al: Identification of three subtypes of triple-negative breast cancer with potential therapeutic implications. Breast Cancer Res 21: 65, 2019.

75. Freier CP, Kuhn C, Endres S, Mayr D, Friese K, Jeschke U and Anz D: FOXP ${ }^{+}$cells recruited by CCL 22 into breast cancer correlates with less tumor nodal infiltration. Anticancer Res 36: 3139-3145, 2016.

76. Gobert M, Treilleux I, Bendriss-Vermare N, Bachelot T, Goddard-Leon S, Arfi V, Biota C, Doffin AC, Durand I, Olive D, et al: Regulatory T cells recruited through CCL22/CCR4 are selectively activated in lymphoid infiltrates surrounding primary breast tumors and lead to an adverse clinical outcome. Cancer Res 69: 2000-2009, 2009. 
77. Pitzalis C, Jones GW, Bombardieri M and Jones SA: Ectopic lymphoid-like structures in infection, cancer and autoimmunity. Nat Rev Immunol 14: 447-462, 2014.

78. Dieu-Nosjean MC, Antoine M, Danel C, Heudes D, Wislez M, Poulot V, Rabbe N, Laurans L, TartourE, de Chaisemartin L, et al: Long-term survival for patients with non-small-cell lung cancer with intratumoral lymphoid structures. J Clin Oncol 26: 4410-4417, 2008.

79. Goc J, Germain C, Vo-Bourgais TK, Lupo A, Klein C, Knockaert S, de Chaisemartin L, Ouakrim H, Becht E, Alifano M, et al: Dendritic cells in tumor-associated tertiary lymphoid structures signal a Th1 cytotoxic immune contexture and license the positive prognostic value of infiltrating $\mathrm{CD}^{+}$ T cells. Cancer Res 74: 705-715, 2014.

80. Horne ZD, Jack R, Gray ZT, Siegfried JM, Wilson DO, Yousem SA, Nason KS, Landreneau RJ, Luketich JD and Schuchert MJ: Increased levels of tumor-infiltrating lymphocytes are associated with improved recurrence-free survival in stage 1A non-small-cell lung cancer. J Surg Res 171: 1-5, 2011.

81. Kim A, Lee SJ, Ahn J, Park WY, Shin DH, Lee CH, Kwon H, Jeong YJ, Ahn HY, I H, et al: The prognostic significance of tumor-infiltrating lymphocytes assessment with hematoxylin and eosin sections in resected primary lung adenocarcinoma. PLoS One 14: e0224430, 2019.

82. Zhu W, Germain C, Liu Z, Sebastian Y, Devi P, Knockaert S, Brohawn P, Lehmann K, Damotte D, Validire P, et al: A high density of tertiary lymphoid structure B cells in lung tumors is associated with increased $\mathrm{CD}^{+}{ }^{+} \mathrm{T}$ cell receptor repertoire clonality. Oncoimmunology 4: e1051922, 2015

83. de Chaisemartin L, Goc J, Damotte D, Validire P, Magdeleinat $P$ Alifano M, Cremer I, Fridman WH, Sautès-Fridman C and Dieu-Nosjean MC: Characterization of chemokines and adhesion molecules associated with $\mathrm{T}$ cell presence in tertiary lymphoid structures in human lung cancer. Cancer Res 71: 6391-6399, 2011.

84. Fridman WH, Galon J, Dieu-Nosjean MC, Cremer I, Fisson S, Damotte D, Pagès F, Tartour E and Sautès-Fridman C: Immune infiltration in human cancer: Prognostic significance and disease control. Curr Top Microbiol Immunol 344: 1-24, 2011.

85. Ogino S, Nosho K, Irahara N, Meyerhardt JA, Baba Y, Shima K, Glickman JN, Ferrone CR, Mino-Kenudson M, Tanaka N, et al: Lymphocytic reaction to colorectal cancer is associated with longer survival, independent of lymph node count, microsatellite instability, and $\mathrm{CpG}$ island methylator phenotype. Clin Cancer Res 15: 6412-6420, 2009

86. McMullen TP, Lai R, Dabbagh L, Wallace TM and de Gara CJ: Survival in rectal cancer is predicted by $\mathrm{T}$ cell infiltration of tumour-associated lymphoid nodules. Clin Exp Immunol 161: $81-88,2010$

87. Remark R, Alifano M, Cremer I, Lupo A, Dieu-Nosjean MC, Riquet M, Crozet L, Ouakrim H, Goc J, Cazes A, et al: Characteristics and clinical impacts of the immune environments in colorectal and renal cell carcinoma lung metastases: Influence of tumor origin. Clin Cancer Res 19: 4079-4091, 2013.

88. Weinstein AM, Giraldo NA, Petitprez F, Julie C, Lacroix L, Peschaud F, Emile JF, Marisa L, Fridman WH, Storkus WJ, et al: Association of IL-36 $\gamma$ with tertiary lymphoid structures and inflammatory immune infiltrates in human colorectal cancer. Cancer Immunol Immunother 68: 109-120, 2019.
89. Muniz LR, Pacer ME, Lira SA and Furtado GC: A critical role for dendritic cells in the formation of lymphatic vessels within tertiary lymphoid structures. J Immunol 187: 828-834, 2011.

90. Mei Z, Liu Y, Liu C, Cui A, Liang Z, Wang G, Peng H, Cui L and Li C: Tumour-infiltrating inflammation and prognosis in colorectal cancer: Systematic review and meta-analysis. Br J Cancer 110: 1595-1605, 2014.

91. Meshcheryakova A, Tamandl D, Bajna E, Stift J, Mittlboeck M, Svoboda M, Heiden D, Stremitzer S, Jensen-Jarolim E, Grünberger T, et al: B cells and ectopic follicular structures: Novel players in anti-tumor programming with prognostic power for patients with metastatic colorectal cancer. PLoS One 9: e99008, 2014.

92. Schweiger T, Berghoff AS, Glogner C, Glueck O, Rajky O, Traxler D, Birner P, Preusser M, Klepetko W and Hoetzenecker K: Tumor-infiltrating lymphocyte subsets and tertiary lymphoid structures in pulmonary metastases from colorectal cancer. Clin Exp Metastasis 33: 727-739, 2016.

93. Gooden M, Lampen M, Jordanova ES, Leffers N, Trimbos JB, van der Burg SH, Nijman $\mathrm{H}$ and van Hall T: HLA-E expression by gynecological cancers restrains tumor-infiltrating CD ${ }^{+}$ T lymphocytes. Proc Natl Acad Sci USA 108: 10656-10661, 2011.

94. Truxova I, Kasikova L, Hensler M, Skapa P, Laco J, Pecen L, Belicova L, Praznovec I, Halaska MJ, Brtnicky T, et al: Mature dendritic cells correlate with favorable immune infiltrate and improved prognosis in ovarian carcinoma patients. J Immunother Cancer 6: 139, 2018.

95. Ladányi A, Kiss J, Somlai B, Gilde K, Fejos Z, Mohos A, Gaudi I and Tímár J: Density of DC-LAMP(+) mature dendritic cells in combination with activated $\mathrm{T}$ lymphocytes infiltrating primary cutaneous melanoma is a strong independent prognostic factor. Cancer Immunol Immunother 56: 1459-1469, 2007.

96. Cipponi A, Mercier M, Seremet T, Baurain JF, Théate I, van den Oord J, Stas M, Boon T, Coulie PG and van Baren N: Neogenesis of lymphoid structures and antibody responses occur in human melanoma metastases. Cancer Res 72: 3997-4007, 2012.

97. Messina JL, Fenstermacher DA, Eschrich S, Qu X, Berglund AE, Lloyd MC, Schell MJ, Sondak VK, Weber JS and Mulé JJ: 12-Chemokine gene signature identifies lymph node-like structures in melanoma: Potential for patient selection for immunotherapy? Sci Rep 2: 765, 2012.

98. Shields JD, Kourtis IC, Tomei AA, Roberts JM and Swartz MA Induction of lymphoidlike stroma and immune escape by tumors that express the chemokine CCL21. Science 328: 749-752, 2010.

This work is licensed under a Creative Commons Attribution-NonCommercial-NoDerivatives 4.0 International (CC BY-NC-ND 4.0) License. 